\title{
Clinical Outcomes of a New Aspheric Monofocal Intraocular Lens
}

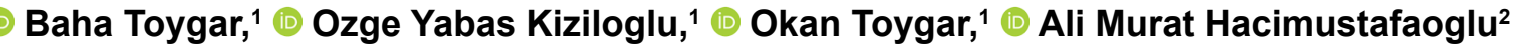 \\ 1Department of Ophthalmology, Bahcesehir University Faculty of Medicine, Istanbul, Turkey \\ ${ }^{2}$ Department of Ophthalmology, Goztepe Medical Park Hospital, Istanbul, Turkey
}

\begin{abstract}
Objectives: This study aims to evaluate the clinical outcomes of a new aberration-free aspheric monofocal intraocular lens (IOL).

Methods: This single-center retrospective study included eyes of cataract patients implanted with a new aberration-free aspheric IOL. Medical records of patients who were followed for 6 months were reviewed. Data on visual acuity (distance, intermediate, and near), refractive error (sphere, cylinder, and manifest spherical equivalent [MSE]), contrast sensitivity, and adverse events were collected and analyzed.

Results: A total of 38 eyes of 30 patients with a mean age of $65.7 \pm 10.6$ years were included in the study. At 6-month post-operative, $100 \%$ of the eyes had achieved a corrected distance visual acuity of 0.2 logMAR or better, $89 \%$ of the eyes had achieved a corrected intermediate visual acuity of $0.2 \log M A R$ or better, and $89 \%$ of the eyes had achieved a corrected near visual acuity of $\mathrm{J} 3$ or better. Postoperatively, there was a significant reduction in the spherical $(p<0.0 \mathrm{I})$ and cylindrical $(p=0.01)$ refraction compared to baseline with a mean final MSE of $-0.03 \pm 0.40$ diopters. Post-operative low contrast (I0\%) visual acuity remained stable $(p=0.54)$ through follow-up visits with a mean of $0.35 \pm 0.17$ logMAR at the 6-month visit. There were no adverse events associated with the study IOL.

Conclusion: The study IOL was safely implanted without any adverse events and improved visual acuity in cataract surgery patients while preserving visual quality over the 6-month follow-up period. Further studies with larger study groups and long-term follow-up are necessary to confirm these results.

Keywords: Aberration-free aspheric monofocal intraocular lens, aspheric monofocal intraocular lens, cataract surgery, intraocular lens, monofocal intraocular lens.
\end{abstract}

\section{Introduction}

Visual acuity and quality outcomes after cataract surgery have improved greatly over the past few decades owing primarily to advances in intraocular lens (IOL) designs (I, 2). While IOLs with spherical optics were traditionally used in cataract surgery, increased awareness about their contribution to post-operative degradation of visual quality led to the creation of aspheric IOLs (3-5).

Spherical IOLs, having positive spherical aberration, in- crease the overall positive spherical aberration of the eye and thus may worsen visual quality. In contrast, aspheric IOLs either induce negative spherical aberration to compensate for the positive aberration of the cornea (aberrationcorrecting IOLs) or they have no spherical aberration at all (aberration-free IOLs) $(3,6)$.

The existing literature shows that IOL implantation is considered a safe, effective, and predictable procedure for replacing a cataractous lens regardless of IOL optics - spherical or aspheric (7). However, analysis of the visual outcomes 
achievable with both IOL types suggests that although little difference exists between them in terms of visual acuity, aspheric IOLs do appear to deliver better contrast sensitivity results than spherical IOLs, especially under low light (I). Several studies have provided results which support claims that aspheric IOLs can significantly improve the quality of vision and increase contrast sensitivity (8-13).

The Optiflex MOFNYAOI monofocal IOL (Moss Vision Inc., Ltd., London, UK) is a new aberration-free hydrophilic acrylic IOL with an aspheric anterior surface designed to restore visual acuity and improve contrast sensitivity in low lighting (14). Since there are little published data describing outcomes following implantation of this IOL, we performed a retrospective analysis to determine if patients implanted with the Optiflex MOFNYAOI IOL achieved the desired visual acuity, refraction, and contrast sensitivity outcomes.

\section{Methods}

\section{Study Design and Patients}

This was a single-center retrospective study investigating the visual outcomes in eyes implanted with the Optiflex MOFNYAOI (Fig. I) by a single surgeon (B.T.). This study was conducted in compliance with the principles of the Declaration of Helsinki, Good Clinical Practices and International Organization for Standardization 14155:20II. All patients provided written informed consent.

Data from pre-operative and post-operative assessments of patients implanted with the study IOL were collected from electronic medical records and analyzed. All included patients were followed for 6 months at regular intervals (at I week; I, 3, and 6 months).

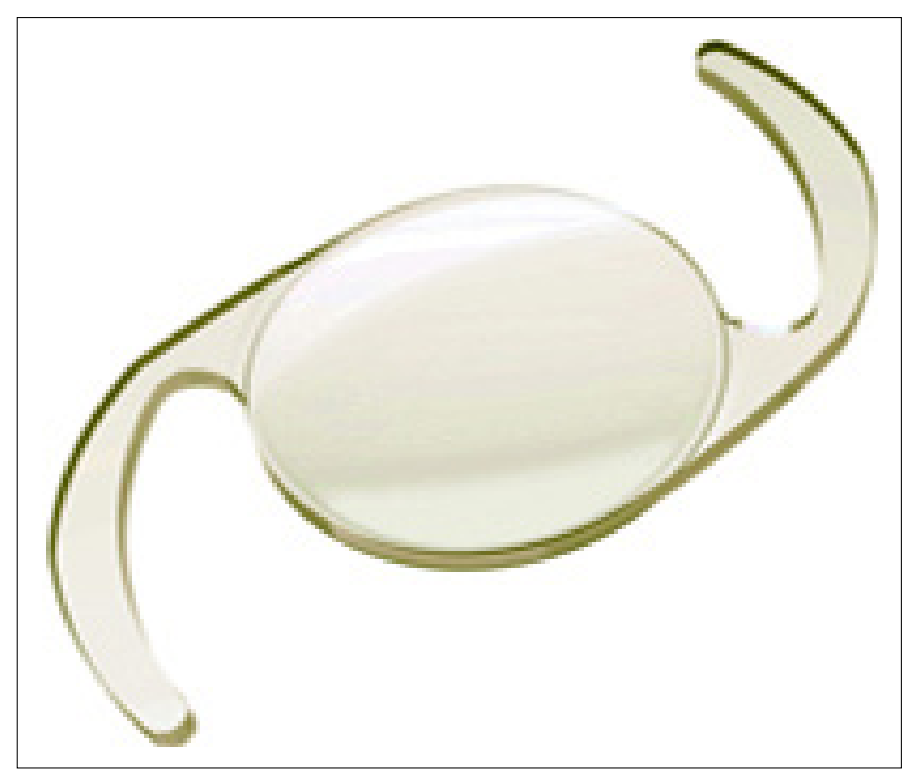

Figure I. The Optiflex MOFNYAOI: single piece $360^{\circ}$ square edge hydrophilic acrylic IOL with aberration-free aspheric optics.
Data collected from pre-operative assessments included uncorrected distance visual acuity (UDVA) and corrected distance visual acuity (CDVA) tested with ETDRS chart at 4 $\mathrm{m}$, refractive status as sphere, cylinder, and manifest spherical equivalent (MSE; value of the sphere plus one-half of the value of the cylinder), optical biometry, and corneal topography measurements. Biometry was performed with IOL Master (Carl Zeiss, Germany). Manual immersion biometry (Nidek, Japan) was performed in eyes in which IOL master could not be used due to the presence of a dense cataract. IOL power was calculated with the SRK-T formula (A constant: I 18.5) in eyes with an axial length (AL) of $22 \mathrm{~mm}$ to $24 \mathrm{~mm}$. The Hoffer $Q$ formula $(P A C D=5.6 \mathrm{I})$ was used in eyes with a shorter $\mathrm{AL}(<22 \mathrm{~mm})$ and the Holladay 2 formula ( $A C D$ constant $=5.607)$ was used in eyes with a longer $A L$ (>24 mm).

Post-operative data collected at I week, I-, 3-, and 6-month visits included UDVA and CDVA with ETDRS chart at $4 \mathrm{~m}$, uncorrected near visual acuity (UNVA) and corrected near visual acuity (CNVA) with the Near Vision Jaeger card at $40 \mathrm{~cm}$, and uncorrected intermediate visual acuity (UIVA) and corrected intermediate visual acuity (CIVA) with the ETDRS card at $80 \mathrm{~cm}$. Refractive status was recorded as in pre-operative assessment. High contrast $(100 \%)$ and low contrast (10\%) visual acuities measured with ETDRS chart at $100 \mathrm{~cm}$ under $85 \mathrm{~cd} / \mathrm{m} 2$ luminance at the 1-, 3-, and 6-month visits were also recorded. Any adverse experiences or complications observed by the investigator or reported by the patients were noted. Exclusion criteria were history of diabetes, preexisting retinal disease or ocular pathology, and previous ocular surgery. Patients with incomplete data were also excluded from the study.

\section{Study IOL}

The Optiflex MOFNYAOI is a single piece, $360^{\circ}$ square edge hydrophilic acrylic IOL with aberration-free aspheric optics. IOL has an overall size of $12.5 \mathrm{~mm}$ and an optic size of $6 \mathrm{~mm}$. IOL is supplied in diopters of +5.0-+30.0 D (with $0.5 \mathrm{D}$ steps from + 15.0 D to $+25.0 \mathrm{D}$ ). It contains a unique covalently bonded patented natural chromophore, which contains the same UV-A blocking and violet light filtering chromophore found in the human crystalline lens.

\section{Statistical Analysis}

The statistical analysis was performed using Statistica (Version 12, Dell Systems, USA). Summary descriptive statistics were produced for all the key variables of the study including the mean, variance, standard deviation and standard error, median, mode, and interquartile range. The data for all variables were examined for normality using a probability plot and a formal test of statistical significance using the Schapiro-Wilk test. Based on the assumption of normal- 
ity, 95\% confidence/fiducial limits were computed. The data were checked for outliers and any suspected outliers were triple-checked for accuracy and precision. For normal data, means were compared within the group using repeated measures ANOVA. For non-normal data, a logarithmic transformation was used to meet the requirements of the ANOVA. Statistical significance was set at $p \leq 0.05$ in all cases.

\section{Results}

A total of 38 eyes of 30 patients were included in the anal$y$ sis. The study population consisted of 20 men and 10 women with an average age of $65.7 \pm 10.6$ years (range: 48 82 years). The mean IOL power was $20.54 \pm \mathrm{I} .30 \mathrm{D}$ (range: 17.50 D-22.50 D).

\section{Visual Acuity}

Distance Visual Acuity: The outcomes for UDVA and CDVA are shown in Table I. UDVA remained stable through 6 months with no statistical difference between visits $(p=0.776)$. At post-operative 6 months, mean UDVA was 0.18 logMAR. Regarding CDVA, there was a significant improvement of four lines on average from the pre-operative visit. Significance was reached at every post-operative visit compared to baseline $(p<0.000 \mathrm{I})$. At the 6-month visit, mean CDVA was $0.04 \log M A R$.

Near Visual Acuity: UNVA and CNVA outcomes are shown in Table 2. No significant differences were found in UNVA between follow-up visits $(p=0.387)$ with a mean UNVA of $\mathrm{J} 10$ at 6-month post-operative. CNVA showed significant improvement at I month $(p=0.0005)$ and 6 months $(p=0.0004)$ compared to I-week post-operative. The mean CNVA was $\mathrm{J} 2$ at 6 months.

Intermediate Visual Acuity: Table 3 shows intermediate visual acuity outcome through 6 months. There was a statistically significant improvement in UIVA across follow-up visits, improving from $0.32 \log M A R$ at week I post-operative to $0.22 \log M A R$ at the 6 -month visit $(p=0.03)$. Significant improvement in CIVA was found at post-operative I-month $(p=0.00 \mathrm{I})$, 3-month $(p=0.003)$, and 6-month $(p<0.000 \mathrm{I})$ visits compared to the I-week visit. At the 6-month visit, the mean CIVA was 0.10 logMAR.

\section{Contrast Sensitivity}

Contrast sensitivity outcomes are shown in Table 4. High $(100 \%)$ and low $(10 \%)$ contrast visual acuity remained stable $(p=0.7 \mathrm{I}$ and $p=0.19$, respectively) through the follow-up period with a mean high contrast visual acuity of $0.15 \pm 0.14$ and low contrast visual acuity of $0.38 \pm 0.10$ logMAR at 6-month visit.

\section{Refraction}

Refractive outcomes are shown in Table 5. There was significant reduction in the spherical component at all post-operative visits compared to baseline. Significant reduction in the cylindrical component was found at post-operative I month and following visits compared to baseline $(p<0.01)$. MSE remained stable $(p=0.053)$ through post-operative visits with a mean of $-0.03 \pm 0.40 \mathrm{D}$ at the 6 -month visit.

\section{Safety Evaluation}

There were no reported adverse events, intraoperative or

Table I. Distance visual acuity after implantation of Optiflex MOFNYAOI IOL

\begin{tabular}{lccc} 
Visit & $\mathbf{n}$ & $\begin{array}{c}\text { CDVA } \\
\text { Mean } \pm S D\end{array}$ & $\begin{array}{c}\text { UDVA } \\
\text { Mean } \pm S D\end{array}$ \\
\hline Pre-operative & 38 & $0.41 \pm 0.27$ & - \\
I-week & 38 & $0.09 \pm 0.10^{*}$ & $0.19 \pm 0.13$ \\
I-month & 38 & $0.04 \pm 0.07^{*}$ & $0.17 \pm 0.12$ \\
3-month & 38 & $0.05 \pm 0.09 *$ & $0.17 \pm 0.14$ \\
6-month & 38 & $0.04 \pm 0.07^{*}$ & $0.18 \pm 0.12$ \\
\hline
\end{tabular}

CDVA: Corrected distance visual acuity; UDVA: Uncorrected distance visual acuity; ${ }^{*}<<0.000 I$ : versus baseline.

Table 2. Near visual acuity after implantation of Optiflex MOFNYAOI IOL

\begin{tabular}{|c|c|c|c|}
\hline $\begin{array}{l}\text { Post-operative } \\
\text { visit }\end{array}$ & $\mathbf{n}$ & $\begin{array}{c}\text { CNVA }^{a} \\
\text { Mean } \pm S D\end{array}$ & $\begin{array}{l}\text { UNVA }^{a} \\
\text { Mean士SD }\end{array}$ \\
\hline I-week & 38 & $3.4 \pm 2.0$ & $10.0 \pm 4.0$ \\
\hline I-month & 38 & $2.1 \pm 1.0$ & $10.0 \pm 4.0$ \\
\hline 3-month & 38 & $2.6 \pm 1.0$ & $11.0 \pm 3.0$ \\
\hline 6-month & 38 & $2.0 \pm 1.0$ & $10.0 \pm 4.0$ \\
\hline
\end{tabular}

CNVA: Corrected near visual acuity; UNVA: Uncorrected near visual acuity; ${ }^{a}$ with NearVision Jaeger chart at $40 \mathrm{~cm}$.

Table 3. Intermediate visual acuity after implantation of Optiflex MOFNYAOI IOL

\begin{tabular}{|c|c|c|c|}
\hline $\begin{array}{l}\text { Post-operative } \\
\text { visit }\end{array}$ & $\mathbf{n}$ & $\begin{array}{c}\text { CIVAa }^{\mathrm{a}} \\
\text { Mean士SD }\end{array}$ & 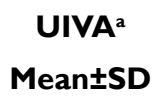 \\
\hline I-week & 38 & $0.22 \pm 0.17$ & $0.32 \pm 0.23$ \\
\hline I-month & 38 & $0.12 \pm 0.13$ & $0.24 \pm 0.17$ \\
\hline 3-month & 38 & $0.12 \pm 0.13$ & $0.28 \pm 0.21$ \\
\hline 6-month & 38 & $0.10 \pm 0.12$ & $0.22 \pm 0.14$ \\
\hline
\end{tabular}

CIVA: Corrected intermediate visual acuity; UIVA: Uncorrected intermediate visual acuity; alogMar, with ETDRS chart at $80 \mathrm{~cm}$. 
Table 4. Contrast sensitivity after implantation of Optiflex MOFNYAOI IOL

\begin{tabular}{lccc} 
Post-operative visit & $\mathbf{n}$ & $\begin{array}{c}\text { High contrast (100\%) } \\
\text { visual acuity } \\
\text { Mean } \pm \text { SD }\end{array}$ & $\begin{array}{c}\text { Low contrast (10\%) } \\
\text { visual acuity } \\
\text { Mean } \pm \text { SD }\end{array}$ \\
\hline I-month & 38 & $0.17 \pm 0.17$ & $0.37 \pm 0.12$ \\
3-month & 38 & $0.16 \pm 0.15$ & $0.41 \pm 0.13$ \\
6-month & 38 & $0.15 \pm 0.14$ & $0.38 \pm 0.10$
\end{tabular}

alogMAR: with ETDRS chart at $100 \mathrm{~cm}$ : under $85 \mathrm{~cd} / \mathrm{m}^{2}$ luminance.

Table 5. Refraction outcomes after implantation of Optiflex MOFNYAOI IOL

\begin{tabular}{|c|c|c|c|c|c|c|}
\hline Visit & $\mathbf{n}$ & $\begin{array}{c}\text { Sphere }^{a} \\
\text { Mean } \pm S D\end{array}$ & P value ${ }^{b}$ & $\begin{array}{l}\text { Cylinder } \\
\text { Mean士SD }\end{array}$ & P value ${ }^{b}$ & MSE $^{\mathbf{a}}$ \\
\hline Pre-operative & 38 & $0.94 \pm 1.74$ & - & $-|| 4 \pm 0.7 \mid$. & - & $0.38 \pm 1.76$ \\
\hline I-week & 38 & $0.36 \pm 0.54$ & 0.012 & $-0.91 \pm 0.56$ & 0.07 & $-0.10 \pm 0.45$ \\
\hline I-month & 38 & $0.36 \pm 0.50$ & 0.014 & $-0.80 \pm 0.64$ & $<0.001$ & $-0.04 \pm 0.41$ \\
\hline 3-month & 38 & $0.36 \pm 0.5 \mathrm{I}$ & 0.012 & $-0.81 \pm 0.59$ & 0.001 & $-0.05 \pm 0.42$ \\
\hline 6-month & 38 & $0.32 \pm 0.50$ & 0.006 & $-0.78 \pm 0.57$ & $<0.001$ & $-0.03 \pm 0.40$ \\
\hline
\end{tabular}

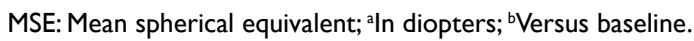

post-operative complications associated with the study IOL that required additional intervention or treatment.

\section{Discussion}

This single-center, retrospective study assessed the refractive outcomes in cataract surgery patients implanted with the aberration-free aspheric Optiflex MOFNYAOI IOL. The findings revealed good visual acuity at 6-month post-operative. Specifically, mean CDVA, CIVA, and CNVA improved significantly over the post-operative period to a CDVA, CIVA, and CNVA of $0.04 \log M A R, 0.10 \log M A R$, and J2, respectively, at 6-month post-operative. Of note, UDVA, UIVA, and UNVA at this time were $0.18 \log M A R, 0.23 \log M A R$, and $\mathrm{J} 10$, respectively, and remained stable or improved through post-operative visits.

While the current study assessed visual acuity at distance, intermediate, and near, there is a notable absence of literature with a comparable study design that has assessed visual acuity in this manner. Nonetheless, published literature suggests that aspheric IOLs with a similar monofocal aberration-free design to that of the study IOL improve postoperative visual acuity measured simply as best-corrected visual acuity (BCVA). For example, in a study by Trueb et al. (10), 524 eyes were implanted with the monofocal aspheric AcrySof IQ IOL (262 eyes) or the spherical AcrySof SN60AT IOL (262 eyes; both Alcon Laboratories, Fort Worth, Texas, USA). At 6-month post-operative, BCVA in both groups had significantly improved from baseline (no intragroup difference). More specifically, the aspheric group achieved a mean BCVA of 0.05 logMAR at post-operative month 6- a result similar to the CDVA of 0.04 achieved in the current study. Of note, Trueb et al. (10) did not state the mean pre-operative BCVA; therefore, it is hard to determine if the overall improvement in visual acuity provided by the aspheric AcrySof IQ is similar to that observed with the use of the Optiflex MOFNYAOI in the current study. However, other studies on the efficacy of the AcrySof, for example, a meta-analysis by Liu et al. (I5) which included 400 eyes implanted with either the spherical AcrySof Natural IOL or the aspheric AcrySof IQ IOL, reported significantly improved visual acuity with the aspheric AcrySof IQ.

In a separate study by Lee et al., (12) the visual outcomes provided by three different aspheric monofocal IOLs implanted in a total of 90 eyes were assessed. IOLs were the Tecnis ZA9003 (Abbott Medical Optics, Santa Ana, California, USA), the AcrySof IQ SN60WF (Alcon Laboratories, Fort Worth, Texas, USA), and the Akreos ADAPT-AO (Bausch and Lomb, Rochester, New York, USA). In keeping with the current study's results, all three IOLs showed similar improvement in UCVA and BCVA (at $4 \mathrm{~m}$ ) at 6-month postoperative. Specifically, UCVA and BCVA were 0.09 and 0.03 logMAR, respectively, for the Tecnis ZA9003 (a respective improvement of -0.35 and $-0.32 \log M A R$ from the pre-operative measurement), 0.06 and $0.01 \log M A R$, respectively, 
for the AcrySof IQ SN60WF (a respective improvement of $-0.4 \mathrm{I}$ and $-0.34 \log M A R$ from the pre-operative measurement), and 0.10 and $0.02 \log M A R$, respectively, for the Akreos ADAPT-AO (a respective improvement of -0.44 and $-0.45 \log M A R$ from the pre-operative measurement). These are comparable to the improvement in CDVA of -0.37 seen in the current study; however, they show an improvement in UCVA that was not reflected by the UDVA of the current study, which remained stable over the follow-up period.

In the present study, there was a significant reduction in the spherical component from baseline at all post-operative visits, exhibiting stability from post-operative week $I$. The pre-operative cylindrical component decreased significantly from post-operative month I onward. The pre-operative MSE of $0.38 \mathrm{D}$ decreased to -0.0 ID evaluated on post-operative month I and was maintained through to post-operative month 6. This finding is similar to that of published studies. The study by Lee et al. (12), for example, did not record pre-operative MSE but revealed no significant difference in the MSE of all three IOLs at 2-month post-operative compared with post-operative month 6 . Thus, the stable postoperative MSE achieved with other IOLs such as the Tecnis ZA9003, the AcrySof IQ SN60WF, and the Akreos ADAPT$A O$ was also found with the study IOL.

In the current study, contrast sensitivity outcome was considered satisfactory, as low (10\%) contrast visual acuity remained stable across the post-operative period with a mean of $0.38 \pm 0.10 \log M A R$ at the last visit. Published studies have also evaluated contrast sensitivity outcomes with a monofocal aspheric IOL. The study by Trueb et al., (10) in which outcomes of the monofocal aspheric AcrySof IQ IOL and the spherical AcrySof SN60AT IOL were compared, it was revealed that the aspheric IOL provided better contrast sensitivity outcomes than the spherical IOL. Given that, the aforementioned study did not indicate how the yielded results with the aspheric IOL changed over time, meaningful comparisons cannot be made between its results and those of the current study. However, the study by Lee et al. (12) revealed that contrast sensitivity under photopic and mesopic conditions was maintained with all three IOLs studied over a 6-month follow-up period.

In the current study group, all surgeries were uneventful and no intraoperative complication was observed. Postoperatively, no adverse event or complication requiring additional treatment or intervention was reported. These findings may indicate that the study IOL has a good safety profile.

The small sample size is the main limitation of the current study. Given this small study size, it is difficult to conclude with a high degree of certainty that the results seen in this study reflect those that are universally achievable with this lens. Further, larger scale studies are required to corrobo- rate the current findings. The short trial length is another notable limitation. Although a 6-month follow-up period is sufficient for demonstrating short-term outcomes obtained with the study IOL, an extended follow-up period of at least 12 months is needed to provide in-depth insight into the visual outcomes that are achievable in the long term. Nonetheless, the current study's findings provide good evidence of the visual capabilities of the study IOL in cataract surgery patients.

\section{Conclusion}

As a conclusion, the Optiflex MOFNYAOI IOL was safely implanted without any adverse events and allowed for improved visual acuity outcomes in cataract surgery patients while preserving contrast sensitivity over a 6-month follow-up period. Further studies with longer follow-up and larger samples are necessary to consolidate the outcomes observed in this study.

\section{Disclosures}

Peer-review: Externally peer-reviewed.

Conflict of Interest: None declared.

Authorship Contributions: Involved in design and conduct of the study (BT, OYK, OT, AMH); preparation and review of the study (BT, OYK, OT); data collection (BT, OYK, AMH); and statistical analysis (OYK, OT, AMH).

\section{References}

I. Schuster AK, Tesarz J, Vossmerbaeumer U. The impact on vision of aspheric to spherical monofocal intraocular lenses in cataract surgery: a systematic review with meta-analysis. Ophthalmology 2013;120:2166-75.

2. Kretz FT, Tandogan T, Khoramnia R, Auffarth GU. High order aberration and straylight evaluation after cataract surgery with implantation of an aspheric, aberration correcting monofocal intraocular lens. Int J Ophthalmol 20I5;8:736-4I.

3. Holladay JT, Piers PA, Koranyi G, van der Mooren M, Norrby NE. A new intraocular lens design to reduce spherical aberration of pseudophakic eyes. J Refract Surg; |8:683-9|.

4. Bellucci R, Morselli S, Piers P. Comparison of wavefront aberrations and optical quality of eyes implanted with five different intraocular lenses. J Refract Surg 2004;20:297-306.

5. Awwad ST, Warmerdam D, Bowman RW, Dwarakanathan S, Cavanagh HD, McCulley JP. Contrast sensitivity and higher order aberrations in eyes implanted with AcrySof IQ SN60WF and AcrySof SN60AT intraocular lenses. J Refract Surg 2008;24:619-25.

6. Altmann GE, Nichamin LD, Lane SS, Pepose JS. Optical performance of 3 intraocular lens designs in the presence of decentration. J Cataract Refract Surg 2005;31:574-85.

7. Ye PP, Li X, Yao K. Visual outcome and optical quality after bilateral implantation of aspheric diffractive multifocal, as- 
pheric monofocal and spherical monofocal intraocular lenses: a prospective comparison. Int J Ophthalmol 2013;6:300-6.

8. Sandoval HP, Fernández de Castro LE, Vroman DT, Solomon KD. Comparison of visual outcomes, photopic contrast sensitivity, wavefront analysis, and patient satisfaction following cataract extraction and IOL implantation: aspheric vs spherical acrylic lenses. Eye (Lond) 2008;22:1469-75.

9. Denoyer A, Denoyer L, Halfon J, Majzoub S, Pisella PJ. Comparative study of aspheric intraocular lenses with negative spherical aberration or no aberration. J Cataract Refract Surg 2009;35:496-503.

10. Trueb PR, Albach C, Montés-Micó R, Ferrer-Blasco T. Visual acuity and contrast sensitivity in eyes implanted with aspheric and spherical intraocular lenses. Ophthalmology 2009; I 16:890-5.

II. Alió JL, Piñero DP, Ortiz D, Montalbán R. Clinical outcomes and postoperative intraocular optical quality with a microin- cision aberration-free aspheric intraocular lens. J Cataract Refract Surg 2009;35:1548-54.

12. Lee KM, Park SH, Joo CK. Comparison of clinical outcomes with three different aspheric intraocular lenses. Acta Ophthalmol 20I I;89:40-6.

13. Nochez Y, Majzoub S, Pisella PJ. Effect of interaction of macroaberrations and scattered light on objective quality of vision in pseudophakic eyes with aspheric monofocal intraocular lenses. J Cataract Refract Surg 2012;38:633-40.

14. OPTIFLEX Aspheric IOL. Available at: http://www.mossvision. co.uk/mossvision-aspehric-iols.php. Accessed Dec 7, 2018.

15. Liu J, Zhao J, Ma L, Liu G, Wu D, Zhang J. Contrast sensitivity and spherical aberration in eyes implanted with AcrySof IQ and AcrySof Natural intraocular lens: the results of a meta-analysis. PLoS One 2013;8:e77860. 